\title{
A CCaMK/Cyclops response element in the promoter of $L$. japonicus Calcium-Binding Protein 1 (CBP1) mediates transcriptional activation in root symbioses
}

\author{
Xiaoyun Gong ${ }^{1}$, Elaine Jensen ${ }^{2,3}$, Simone Bucerius $^{1}$ \& Martin Parniske ${ }^{1,2^{*}}$
}

\section{Affiliations}

1 Genetics, Faculty of Biology, LMU Munich, Grosshaderner Str. 2-4, D-82152 Martinsried, Germany

2 The Sainsbury Laboratory, Colney Lane, Norwich, NR4 7UH, United Kingdom

3 Institute of Biological, Environmental and Rural Sciences, Aberystwyth University, Aberystwyth, Ceredigion, SY23 3EB, Wales, United Kingdom

*Corresponding author: parniske@Imu.de

\section{Summary}

Early gene expression in arbuscular mycorrhiza (AM) and the nitrogen-fixing root nodule symbiosis (RNS) is governed by a shared regulatory complex. Yet many symbiosis-induced genes are specifically activated in only one of the two symbioses. The Lotus japonicus T-DNA insertion line T90, carrying a promoterless uidA (GUS) gene in the promoter of Calcium Binding Protein1 (CBP1) is exceptional as it exhibits GUS activity in both root endosymbioses. To identify the responsible cis- and trans-acting factors, we subjected deletion/modification series of CBP1 promoter:reporter fusions to transactivation and spatio-temporal expression analysis and screened EMS-mutagenized T90 populations for aberrant GUS expression. We identified one cis-regulatory element required for GUS expression in the epidermis and a second element, necessary and sufficient for transactivation by the Calcium and Calmodulindependent protein kinase (CCaMK) in combination with the transcription factor Cyclops and conferring gene expression during both AM and RNS. Lack of GUS expression in T90 white mutants could be traced to DNA hypermethylation detected in and around this element. We concluded that the CCaMK/Cyclops complex can contribute to at least three distinct gene expression patterns on its direct target promoters NIN (RNS), RAM1 (AM), and CBP1 (AM and RNS), calling for yet-to-be identified specificity-conferring factors.

\section{Key words}

nitrogen-fixing root nodule symbiosis; arbuscular mycorrhizal symbiosis; transcriptional regulation; tissue specificity; epigenetic modification; T-DNA insertion; EMS mutagenesis; DNA methylation 


\section{Introduction}

As main constituents of nucleotides, proteins and nucleic acids, nitrogen and phosphate are essential for life (Bowler et al., 2010). Two types of plant root endosymbiosis, the arbuscular mycorrhiza (AM) and the nitrogen-fixing root nodule symbiosis (RNS) hold promise for sustainable agriculture. AM and RNS greatly benefit plant nutrition by improving nutrient uptake from the soil and providing ammonium as a nitrogen source, respectively. RNS can significantly reduce the demand for chemical nitrogen fertiliser application, hence reducing fossil fuel consumption and, once globally adjusted to a sustainable scale, the negative ecological impact imposed by the release of ammonium and nitrogen oxides into the atmosphere, groundwater, rivers, lakes and the sea (Fowler et al., 2013).

Establishment of both $\mathrm{AM}$ and RNS requires chemical communications between symbiotic partners that induce concerted structural modification and rearrangement of the host cells, both controlled by a cohort of transcriptional circuitries. To unravel the genes underlying the development of these two important symbioses, transcriptome analysis has been employed and led to a catalogue of symbiosis-regulated genes that are responsive to AM (Liu et al., 2003; Kistner et al., 2005; Hogekamp et al., 2011; Gutjahr et al., 2015) or RNS (Demina et al., 2013; Breakspear et al., 2014; Roux et al., 2014). Although many symbiosis regulated genes are expressed specifically in either RNS or AM, such as Nodule Inception (NIN) (Schauser et al., 1999; Kumar et al., 2020) or Reduced Arbuscular Mycorrhiza 1 (RAM1) (Gobbato et al., 2012), respectively, a small subset of genes appears to be induced in both symbioses. These include a symbiosis induced Subtilase (SbtS) (Kistner et al., 2005; Takeda et al., 2007, 2009), Vesicle-Associated Membrane Protein 72 (Ivanov et al., 2012), ENOD11 (Boisson-Dernier et al., 2005), Vapyrin (Murray et al., 2011) and ABC-B transporters in Mycorrhization and Nodulation genes (Roy et al., 2021).

The question how the three different patterns of gene expression in response to symbiotic bacteria and fungi are accomplished, is particularly puzzling, because early gene expression in both symbioses depends on the same subset of the so called "common symbiosis genes", some of which encode proteins involved in early signal transduction processes (Kistner et al., 2005; Oldroyd, 2013). A key to specificity may be at the initiation step of the signalling cascade because microsymbiont-derived molecules, lipochitooligosaccharides (LCOs) with specificity-conferring decorations produced by nitrogenfixing bacteria (collectively referred to as Nod factor), or LCOs and short chain chitin oligosaccharides (COs) by AM fungi (Maillet et al., 2011; Radutoiu et al., 2019) are believed to be perceived by distinct complexes comprising LysM type receptor-like kinases (Radutoiu et al., 2003; Zhang et al., 2021). Symbiosis Receptor-like Kinase (SymRK) (Endre et al., 2002; Stracke et al., 2002) can associate with specific LysM receptors and thus forms a conceptual link between the perception of microbial $(L) C O s$ and the initiation of symbiotic downstream 
responses (Ried et al., 2014; Antolín-Llovera et al., 2014). A hallmark of the common signalling process is the generation of nuclear calcium oscillation (or spiking) (Sieberer et al., 2009) facilitated by ion channels and transporters on the nuclear envelope (see review by Kim et al., 2019). Calcium spiking is postulated to act as a second messenger which is presumably decoded in the nucleus by a Calcium-Calmodulin dependent kinase (CCaMK) (Lévy et al., 2004; Tirichine et al., 2006). CCaMK is activated via binding of a, yet to be identified, calmodulin, and interacts with and phosphorylates Cyclops, a DNA-binding transcription factor (Yano et al., 2008; Miller et al., 2013; Singh et al., 2014). This protein complex is required for both RNS and AM to activate symbiosis-related genes, e.g. RAM1 during AM (Pimprikar et al., 2016); or NIN and ERF Required for Nodulation 1 (ERN1) during RNS (Singh et al., 2014; Cerri et al., 2017).

Cis-acting regulatory sequences (cis-elements) are crucial for temporal and/or spatial regulation of gene expression in eukaryotes. In agreement with this, RNS or AM-related ciselements have been identified in the promotors or intronic regions of symbiosis-regulated genes (Pimprikar \& Gutjahr, 2018; Liu et al., 2019; Akamatsu et al., 2020). Taking into account the three principally different expression patterns (AM-induced, RNS-induced and commonly induced) in the light of the postulate of a common symbiosis signalling pathway, it was hypothesised that the different gene expression patterns are achieved by two independent and symbiosis-specific pathways that act in parallel to the common signalling pathway (Schultze \& Kondorosi, 1998). According to this model, dual gene expression in both symbioses could be achieved by promoters harbouring both AM-specific and RNS-specific cis-elements, thus accumulating the output of the two specific and independent pathways, or cis-elements exclusively responsive to the output of the common symbiosis pathway, or a mix of all three types of cis-elements.

To obtain further insights into the mechanisms that confer common symbiosis-related gene expression, we employed the Lotus japonicus promoter tagging line T90 (Webb et al., 2000), which has served as a useful marker line for the study of plant symbiotic signal transduction over the last two decades (Kistner et al., 2005; Gossmann et al., 2012; Ried et al., 2014; Banhara et al., 2015). T90 carries a single copy of a T-DNA, containing a promoterless GUS gene, which is inserted in the promoter region of the Calcium Binding Protein 1 gene (CBP1; Fig. 1a). The T90 GUS gene expression was so far exclusively observed in plant roots inoculated with AM fungi (Kistner et al., 2005) or rhizobia, including Mesorhizobium loti strain R7A in an NF-dependent manner (Webb et al., 2000) and treated with M. loti strain R7A Nod factor (Gossmann et al., 2012; Webb et al., 2000; Fig.1b \& S1) but in no other tissues or treatments tested (Kistner et al., 2005; Gossmann et al., 2012). For example, T90 GUS expression was neither detected in T90 shoots or leaves nor inducible by synthetic hormones 1-Naphthaleneacetic acid (NAA) or 6-Benzylaminopurine (6-BAP) (Webb 
et al., 2000; Tuck, 2006). It was also not induced upon inoculation with the growth-promoting fungus Serendipita indica (previously known as Piriformospora indica) (Banhara et al., 2015).

This work aimed to decipher the molecular secret behind the common, yet exclusive symbiosis-induced gene expression pattern of T90. To this end, we performed a classical "forward genetics" approach in which we generated an ethyl methanesulfonate-mutagenised T90 population and screened $\mathrm{M}_{2}$ and $\mathrm{M}_{3}$ families for the loss and gain of GUS expression. In parallel, we used promoter deletion series to identify regions with relevance for symbiotic responsiveness.

\section{Material and Methods}

Plant, bacterial and fungal material is listed in Method S1.

Plant growth conditions and phenotypic analysis for plants shown in each figure is included in Method S2.

\section{Promoter analysis and microscopy}

Lotus japonicus hairy roots were generated using an Agrobacterium rhizogenes based protocol (Charpentier et al., 2008) with the following modifications: 1) roots of seedlings were cut away while seedlings were immersed in $A$. rhizogenes that was re-suspended in sterile MilliQ water; 2) after removal of roots, shoots of the seedlings were transferred to plates containing Gamborg's B5 medium (without sucrose) and $0.8 \%$ BD Bacto ${ }^{\mathrm{TM}}$ agar. The T-DNA region of the construct carried in $A$. rhizogenes contained a GFP transformation marker (Ubi10 pro:NLS-2xGFP) and a promoter:GUS reporter fusion placed in tandem. Chimeric root systems with transformed roots and/or nodules were identified by GFP fluorescence emanating from nuclei under a Leica MZ16 FA fluorescent stereomicroscope equipped with a GFP3 filter (Leica Microsystems). Transformed nodule primordia and nodules were identified by the presence of a red fluorescence signal under a DsRed filter 10 to $14 \mathrm{dpi}$, then excised and subject to GUS staining for $3 \mathrm{~h}$ at $37^{\circ} \mathrm{C}$ (Groth et al., 2010 with incubating time adjusted). The whole root systems were subjected to GUS staining for $6 \mathrm{~h}$ to investigate the GUS activity across the whole roots (Fig. 3,S3,S5). For promoter analysis of mycorrhized roots, roots were subject to GUS staining for 14 to $16 \mathrm{~h}$ at $37^{\circ} \mathrm{C}$, followed by staining with WGA (Method S3). Microscopic procedure is detailed in Method S4.

\section{DNA constructs}

A detailed description of the constructs used in this study is provided in Table S2. Constructs were generated with the Golden Gate cloning system described in Binder et al. (2014). A variant of the GUS gene, DoGUS (from plasmid C204, DNA Cloning Service), adapted for the Golden Gate cloning system was kindly provided by David Chiasson (SMU, Halifax, Canada). 


\section{EMS mutagenized T90 population and mutant screening}

Generation of the ethyl methane sulphonate (EMS) mutagenized T90 population is described in the Lotus japonicus handbook section 'EMS mutagenesis' (Márquez, 2005). Details of how plants were grown and screening was carried out are listed in Method S5.

\section{Transient expression assays in Nicotiana benthamiana leaves}

$N$. benthamiana plants were grown as previously described (Cerri et al., 2017), and infiltration of $N$. benthamiana leaves with $A$. tumefaciens was performed as previously described (Cerri et al., 2012) but with acetosyringone concentration modified to $150 \mu \mathrm{M}$. A. tumefaciens carrying promoter:GUS fusion constructs of interest (strain AGL1) were coinfiltrated with $A$. tumefaciens containing plasmid $35 S_{\text {pro: }} 3 x H A-C y c l o p s$ (strain AGL1; Singh et

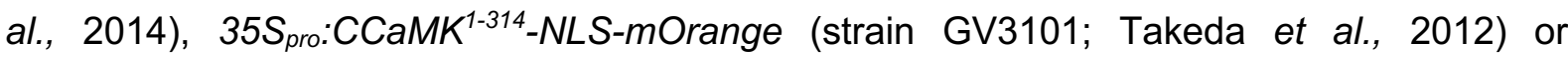
35S pro: $: C C a M K^{T 265 D}-3 x H A$ (strain GV3101; Banba et al., 2008) as indicated in Fig. 5 \& S3. An AGL1 strain carrying a K9 plasmid constitutively expressing Discosoma sp. red fluorescent protein (DsRed) was used as needed to equalize the amount of $A$. tumefaciens infiltrated per leaf, together with an A. tumefaciens strain carrying a plasmid for the expression of the viral P19 silencing suppressor to reduce post-transcriptional gene silencing (Voinnet et al., 2003). $N$. benthamiana leaf discs with a diameter of $0.5 \mathrm{~cm}$ were harvested at 60 hours post infiltration. A total number of 8 leaf discs per indicated vector combination were analysed in at least 2 independent experiments performed in different weeks.

\section{Quantitative fluorometric GUS assay and analysis}

Nicotiana benthamiana leaf discs were subjected to a quantitative fluorometric GUS assay (Jefferson 1987) adapted for 96-well plate format. A total number of four to eight leaf discs per indicated combinations was analysed in at least two independent experiments performed in different weeks.

Genomic DNA extraction and investigation of promoter methylation pattern is detailed in Method S6.

\section{Data visualization and statistical analysis}

Statistical analyses and data visualization were performed with RStudio 1.1. 383 (RStudio Inc.). Boxplots were used to display data in Fig 2, S3 \& S5 (Wickham \& Stryjewski, 2011). Individual data points were added to boxplots using R package "beeswarm" (https://github.com/aroneklund/beeswarm). R package "agricolae" (Mendiburu 2017) was used to perform ANOVA statistical analysis with post hoc Tukey. Statistical results were presented in small letters where different letters indicate statistical significance, while overlapping letters indicate no significant statistical difference. 


\section{Results}

\section{T90 white mutants were identified from an EMS-mutagenised T90 population}

To identify the regulators of the T90 GUS gene, we performed two independent forward genetic screens. The rationale was as follows: mutants with altered GUS activity (and/or impaired symbiotic behaviour) likely possess defects in the regulatory machinery that directly or indirectly regulate the transcription of the GUS gene. Given that transcriptional activation of the GUS gene in T90 occurs in response to symbiotic interactions, these impaired machineries potentially regulate gene expression in AM and/or RNS. An EMS-mutagenised T90 $\mathrm{M}_{2}$ population was generated by separately harvesting seeds of $1342 \mathrm{M}_{1}$ plants labelled T0001T1342. Two independent screens were conducted at the seedling stage utilising individual $M_{2}$ families to identify $(A)$ individual $M_{2}$ plants displaying spontaneous activation of the GUS gene in the absence of symbionts or (B) individual $M_{2}$ plants with altered GUS activity in presence of $M$. loti (Fig. 2a; for further details see Tuck 2006). For this purpose, root pieces were removed and stained with 5-bromo-4-chloro-3-indolyl- $\beta$-D-glucuronic acid (X-Gluc) whereas the rest of the seedling was maintained to allow for seed production and analysis of heritability. Screen $A$ of $519 M_{2}$ and $203 M_{3}$ lines resulted in 84 plants from 55 lines which showed spontaneous GUS expression in the roots, however no progenies from them inherited this

(a)

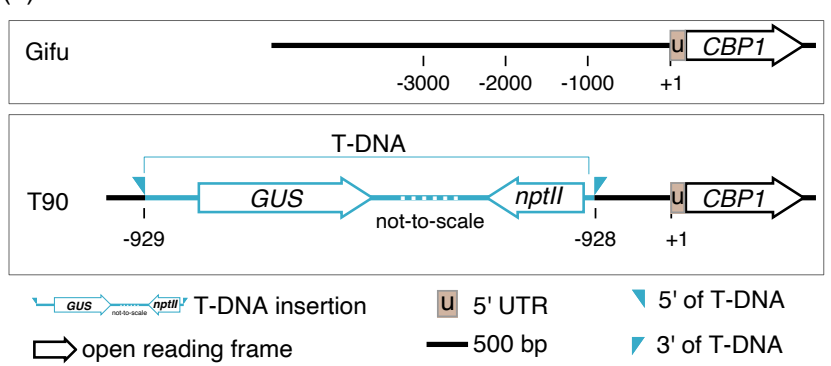

(b)

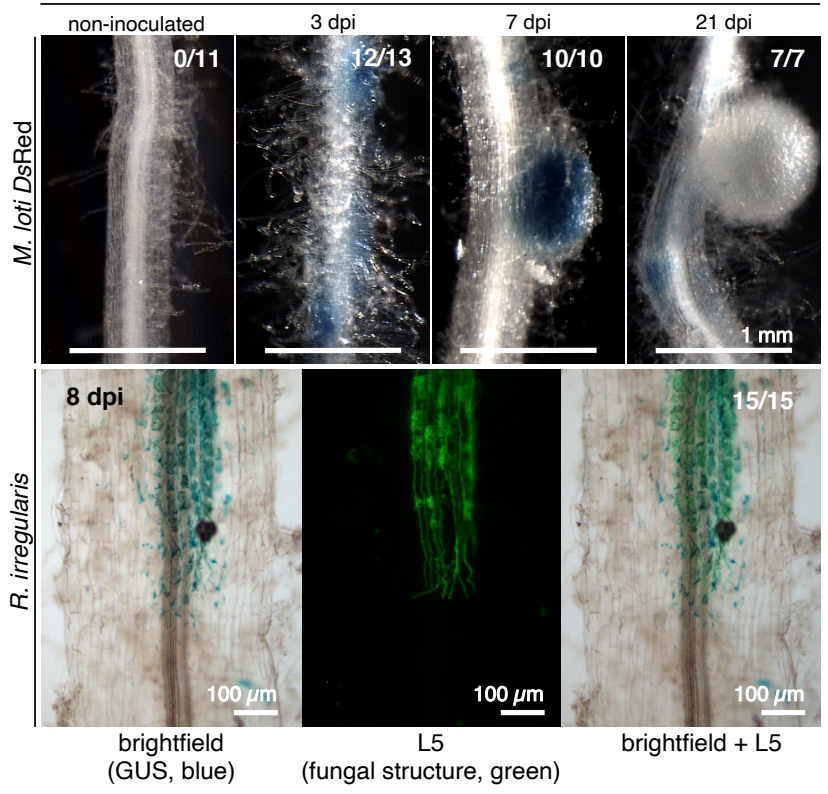

Fig. 1 GUS expression pattern in T90 roots. (a) Position of the T-DNA insertion within the promoter of CBP1 gene in the transgenic line T90. The respective region in $L$. japonicus ecotype Gifu is shown as a reference. (b) T90 roots were stained with X-Gluc to reveal a blue coloration generated by GUS enzyme activity at indicated days post inoculation (dpi) with M. loti DsRed or AM fungus Rhizophagus irregularis. Note the blue staining at $3 \mathrm{dpi}$ in patches in root hair cells, the presence and absence of blue staining in the central nodule tissue at $7 \mathrm{dpi}$ and $21 \mathrm{dpi}$, respectively. Green: Alexa Fluor-488 WGA-stained $R$. irregularis visualised with a Leica Filter Cube L5. \#/\# place top right corner in (b): number of plants displaying GUS activity / total number of plants analysed. Sections of nodules or roots are displayed in Fig. S1. 
phenotype. Screen B of $709 \mathrm{M}_{2}$ lines for loss of $M$. loti-induced GUS activity, resulted in three lines that exhibited heritable aberrant GUS phenotypes. In detail, three $\mathrm{M}_{2}$ plants (L8668 and L8686-8687, progeny from $\mathrm{M}_{1}$ plant T614 and T1305, respectively), were identified that did not exhibit blue staining after incubation with $M$. loti. Based on the white colour of their roots after GUS staining, these three plants were renamed T90 white mutants (L8668 white1, L8686 white2 and L8687 white3) and allowed to self-fertilize. The progeny of all three T90 white plants displayed normal shoot and root morphology and could successfully establish AM and RNS similarly as T90 and L. japonicus Gifu (Fig. S2a-b), however GUS activity could not be detected in their roots during both symbioses (Fig. 2b, S2c-d). T90 white2 was less healthy than white3 and produced limited seeds at the time of this study; therefore, only the progeny of T90 white 3 was included in some subsequent experiments.

\section{T90 GUS expression is genetically located downstream of the common symbiosis genes}

All three T90 white mutants were able to establish both RNS and AM without apparent defects, indicating that essential genes for establishment of symbioses were intact. We sequenced the endogenous GUS gene in T90 white mutants and did not detect alterations in its coding sequences, hence ruling out that mutations in the endogenous GUS genes caused the T90 white phenotype. For the cause of T90 white phenotype, we considered two possible scenarios: 1) a pathway independent of essential symbiosis genes is involved in activation of

(a)

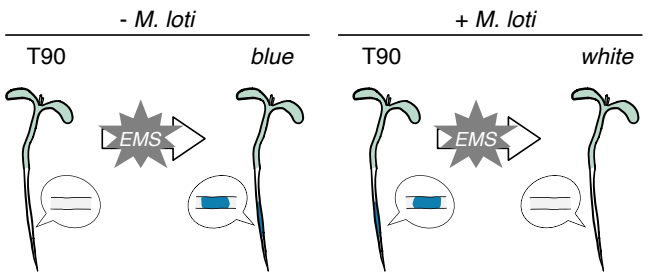

(b)

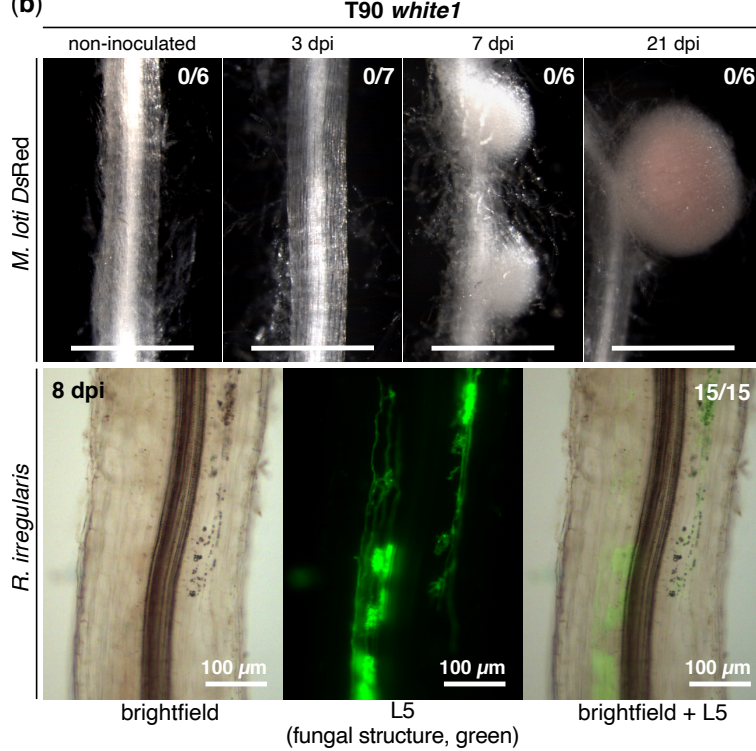

Fig. 2 Absence of GUS activity in T90 white mutant roots during AM or RNS. (a) Schematics of the two screens of EMSinduced mutant populations for $\mathrm{M}_{2}$ seedlings with altered GUS activity: spontaneous activation of the GUS gene in the absence of symbionts (left) or undetectable GUS activity in the presence of symbionts (right; resulting mutants are referred to as T90 white mutants). (b) T90 white1 roots were stained with X-Gluc to reveal GUS activity at indicated dpi with $M$. loti DsRed or $R$. irregularis. Note the total absence of GUS activity in T90 white roots, compared to those of T90 upon inoculation with microsymbionts (tested side-by-side in the same experiment; see Fig. 1a; Fig. S1). Pictures of T90 white1 root systems and analysis of T90 white 3 are included in Fig. S2c-d. Green: Alexa Fluor488 WGA-stained $R$. irregularis visualised with a Leica Filter Cube L5. \#/\# top right corner of images: number of plants displaying GUS activity / total number of plants analysed. 
the T90 GUS gene, which is defective in T90 white; 2) the regulatory region of the GUS gene is defective in T90 white leading to aberrant GUS gene induction. To investigate these possible scenarios, we sought to resolve the connection of the transcriptional activation of the T90 GUS gene to that of symbiosis signalling by crossing the T90 GUS insertion into homozygous backgrounds for mutant alleles of common symbiosis genes. These included mutant allele ccamk-2 for CCaMK [line cac57.3, Schauser et al., 1998, Perry et al., 2009)], symrk-10 for SymRK (Perry et al., 2003), nfr1-1 for the nod factor receptor gene Nod Factor receptor 1 (NFR1) (Radutoiu et al., 2003) and pollux-1 for the cation channel Pollux (EMS70; Szczyglowski et al., 1998). Preliminary results showed that the $F_{2}$ plants from the following crosses, ccamk-2 x T90, nfr1-1 x T90 and T90 x symrk-10 (Gossmann et al., 2012) did not respond with GUS expression after M. loti inoculation. Based on these findings, we concluded that the T90 GUS gene expression is dependent on the tested genes, and positioned the transcriptional activation of the T90 GUS gene downstream of NFR1, SymRK, Pollux and CCaMK. Consistent with this model, ectopically expressed SymRK in T90 hairy roots was able to induce the T90 GUS expression (Ried et al., 2014).

We tested whether the T90 GUS gene expression can be activated by transgenically expressed autoactive CCaMK ${ }^{\mathrm{T} 265 \mathrm{D}}$ in T90 and T90 white mutants' hairy roots. These T90 hairy roots spontaneously induced GUS expression in the absence of a microsymbiont (Gossmann, 2011).

(a)

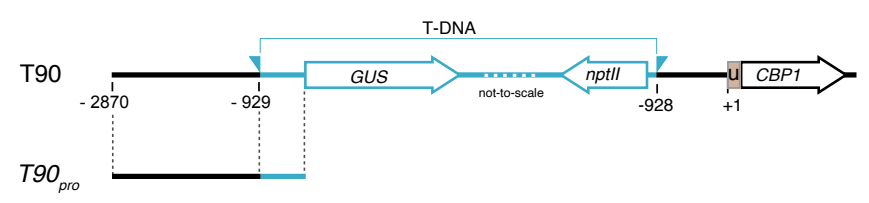

(b)

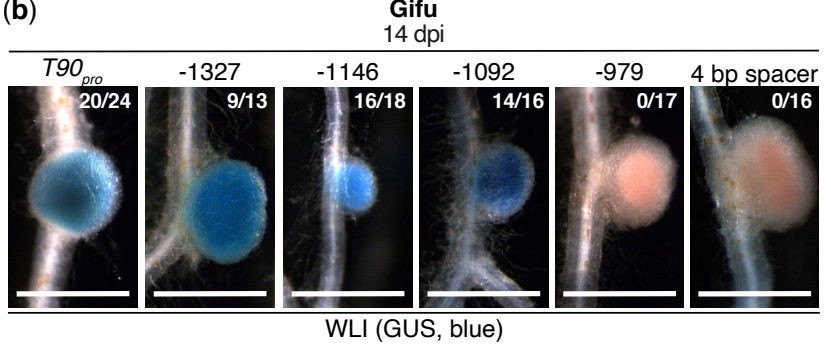

(c)

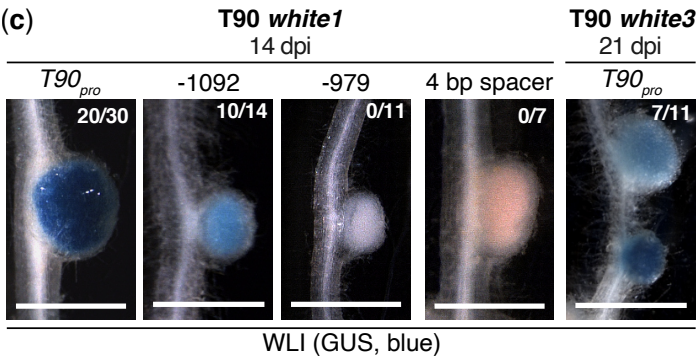

Fig. 3 Absence of GUS activity in T90 white mutants can be restored by transgenic $T 90_{\text {pro: }}$ GUS fusions. (a) TDNA insertion in the T90 line as in Fig. 1 , here including the CBP1 promoter reference coordinates used for definition of the length of the individual fragments tested in the T90 promoter deletion series (for symbols refer to Fig. 1b). (b) L. japonicus Gifu or (c) T90 white mutants (white 1 or white 3 ) hairy roots transformed with T-DNAs carrying a Ubq10 pro:NLS-GFP transformation marker together with a GUS reporter gene driven by the full length T90 promoter (-2870) or a deletion series thereof (starting at $-1327,-1146,-1092$ or -979 of the CBP1 promoter), or a $4 \mathrm{bp}$ spacer sequence were analysed at indicated with M. loti DsRed. Pictures of entire root systems from these experiments are included in Fig. S3a-b. \#/\#: number of plants showing GUS activity in nodules / total number of transgenic root systems analysed. BF: brightfield. Bars, $1 \mathrm{~mm}$ unless stated otherwise. WLI: white light illumination. 
Importantly, Agrobacterium rhizogenes, a member of the Rhizobiaceae and frequently used for hairy root transformation, did not induce the GUS expression in T90 (Gossmann, 2011), supporting that the observed spontaneous GUS induction resulted from transgenically expressed CCaMK ${ }^{\mathrm{T} 265 \mathrm{D}}$. By contrast, we did not observe spontaneous induction of GUS expression by CCaMK ${ }^{\mathrm{T} 265 \mathrm{D}}$ in T90 white 1 and T90 white 3 hairy roots (data not shown). These data provide independent evidence for the position of the T90 GUS expression downstream of CCaMK. The observation that T90 but not T90 white mutants responded with GUS expression to autoactive $\mathrm{CCaMK}^{\mathrm{T} 265 \mathrm{D}}$ combined with the fact that CCaMK phosphorylates and interacts with Cyclops for activation of downstream genes during symbiosis (Singh et al., 2014; Pimprikar et al., 2016; Cerri et al., 2017), motivated us to investigate a possible involvement of Cyclops in the T90 white phenotype. We therefore sequenced Cyclops in T90 white mutants to test for the unlikely case that mutations in the gene prevented GUS genes induction, without influencing symbiosis per se. We did not detect any sequence alterations of the Cyclops gene in all three mutant lines.

\section{Transgenic insertion of a T90 promoter:GUS fusion in the T90 white mutant background restored symbiosis-inducible GUS expression}

Based on the observed dependency of T90 GUS expression on genes involved in early symbiotic signalling, together with the success of T90 white to form both RNS and AM, we hypothesized that these symbiosis genes are likely functional in T90 white. We consequently redirected our focus onto the regulatory region of the T90 GUS gene. To this end we cloned a chimeric region of 2530 bp directly 5 ' of the GUS gene in T90, hereafter called "T90 promoter". This region comprised a 1942 bp fragment positioned between -2870 bp to -929 bp relative to the transcriptional start site of $C B P 1$, followed at the 3' end by 588 bp of the T-DNA sequence 5 ' of the ATG of the GUS gene (Fig. 3a). This fusion is identical to the original T90 fusion and contains all elements necessary for the transcription of the GUS gene, such as a minimal promoter and a transcriptional start site (Jefferson et al., 1987; Topping et al., 1991). We transformed $L$. japonicus Gifu hairy roots with T-DNAs containing a GUS reporter gene driven by the T90 promoter ( $T 90_{\text {pro: }}$ GUS) and analysed the GUS expression in the transgenic roots followed by inoculation with M. loti MAFF 303099 DsRed (M. loti DsRed). Upon exposure of roots to X-Gluc, blue staining indicative of GUS expression was detected exclusively in root hairs (Fig. S3c) and nodules (Fig. 3a,S3a). By contrast, T90 pro:GUS-transformed roots grown in the absence of microsymbionts or roots transformed with an identical construct in which the T90 promoter was replaced by a 4 bp spacer sequence did not exhibit any blue staining (Fig. 3a,S3a). The staining pattern achieved by the $T 90_{\text {pro: }}$ GUS fusion in transgenic roots resembled strongly the pattern observed in T90 completely matching each other in all key aspects investigated: expression in response to $M$. loti inoculation exclusively in root hairs in early infection stage and later in nodules, which eventually disappeared in mature nodules. 
We sequenced the corresponding T90 promoter region of the three T90 white mutants and could not detect any sequence alteration (data not shown). We consequently hypothesised that these mutants may suffer from an epigenetic change that renders its corresponding T90 promoter region non-functional. To test this hypothesis, T90 white1 and white 3 hairy roots were transformed with the $T 90_{\text {pro: }}$ GUS reporter fusion construct which gave nodulation-specific GUS expression in L. japonicus Gifu hairy roots and analysed the GUS expression after inoculation with M. loti DsRed. Because the endogenous GUS genes in the T90 white mutants were not induced during nodulation, any detected blue staining could only result from expression of the introduced reporter gene. Blue staining could be observed in root hairs (Fig. S3c) and nodules (Fig. 3b,S3b) in transformed roots of both T90 white1 and white3. By contrast, T90 white1 hairy roots transformed with a GUS reporter gene driven a 4 bp spacer sequence did not exhibit any blue staining (Fig. 3b,S3b). When these transgenic roots were grown in the absence of microsymbionts, no blue staining was observed. These observations suggested that the machinery targeting the T90 promoter to induce gene expression during nodulation is intact in T90 white mutants and supported the hypothesis that epigenetic changes block the expression of the endogenous GUS genes in T90 white mutants.

\section{A 54 bp and a 113 bp region in the T90 promoter are required for tissue specific expression}

To further dissect the promoter and identify relevant regions and cis-elements, we generated 5 ' deletion series of the T90 promoter in the context of the $T 90_{\text {pro: }}$ GUS reporter fusion (starting at -2870 bp relative to the CBP1 transcriptional start site), without modifications of the rest of the promoter or reporter. The resulting individual constructs started at -1327 , 1146, -1092 and -979 bp (Fig. 2c) and were introduced individually into $L$. japonicus Gifu or T90 white1 hairy roots. Blue staining was observed in nodules transformed with either of the T90 promoter:GUS fusions starting at $-1327,-1146$ or -1092 bp (Fig. 3b). Further deletion to $979 \mathrm{bp}$, as well as promoter replacement with a $4 \mathrm{bp}$ spacer sequence eliminated blue staining in nodules (Fig. 3b). An identical pattern was observed in hairy roots of T90 white 1 where a 1092 bp region could achieve GUS activity in transgenic nodules, but not a -979 bp region (Fig. 3c). We also observed blue staining in patches of root hairs of Gifu and T90 white roots transformed with the GUS reporter gene driven by $T 90_{\text {pro }}$ or a shorter promoter -1146 bp (Fig. S4c), fully resembling the T90 GUS pattern in the root epidermis (Fig. 1b,S1). The epidermal blue staining was no longer detected when a region -1092 bp was tested (Fig. S4c). This 54 bp region (-1146 to $-1092 \mathrm{bp}$ ) was therefore called the "Root Hair Element in the CBP1 promoter" $\left(R H E_{C B P 1}\right)$. We concluded based on these findings that a region of $113 \mathrm{bp}(-1092$ to $-979 \mathrm{bp}$ ) and a stretch of $54 \mathrm{bp}$ located directly 5' (-1146 to -1092 bp; $R H E_{C B P 1}$ ) was necessary for gene expression in nodules and the root epidermis, respectively. 
(a)
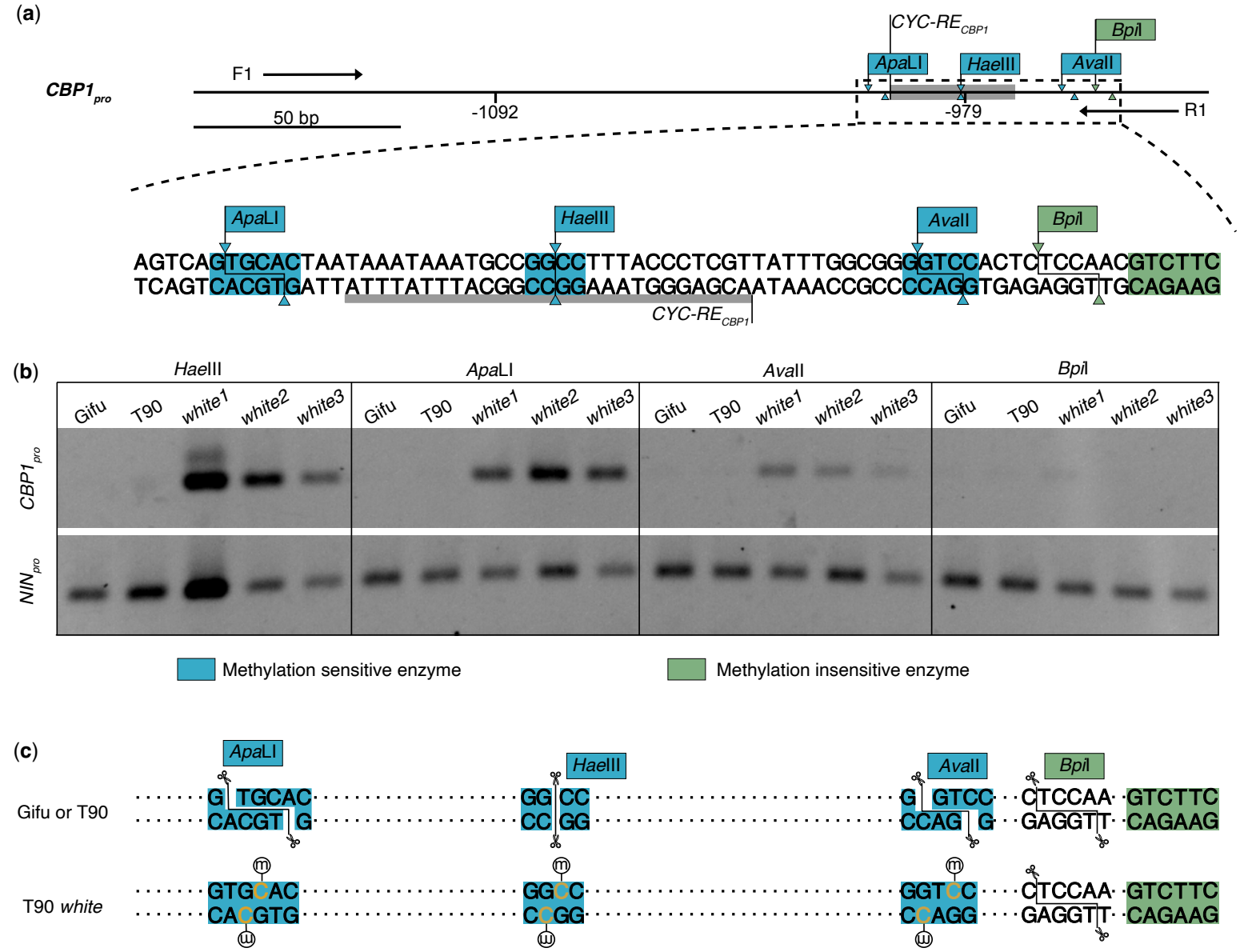

Fig. 4 Cytosine methylation within and around a 113 bp T90 promoter region of T90 white mutants but not those of T90 or L. japonicus Gifu. (a) Genomic DNA (gDNA) from L. japonicus Gifu, T90 or T90 white mutants (white1, white2 or white3) was digested with either one of the restriction digestion enzymes: methylation-sensitive restriction enzymes Haelll, ApaLI and Avall (blue) or methylation-insensitive restriction enzyme Bpil (green). Blue and green shades on DNA sequence: recognition sites of restriction enzymes. Grey shade in the restriction map or grey underline of promoter sequence: $C Y C-R E_{C B P 1}$. Arrowheads and lines: endonucleolytic cleavage site and outline of the restriction digestion products. (b) Analysis of the success of restriction digestion by PCR. Digested gDNA from the indicated genotype was used as a template for PCR amplification with primers F1 and R1 flanking a 262 bp promoter region (top panel) and primers flanking a $199 \mathrm{bp}$ stretch of the L. japonicus NIN promoter as control (bottom panel). This region in the NIN promoter does not contain restriction sites for any of the restriction enzymes used. This control indicates that the status of the gDNA was suitable for PCR after the digestion process. Note that PCR products could be obtained using digested gDNA from the T90 white mutants but not from Gifu or T90 as amplification template. (c) Graphic summary of the results in (b) projected onto the promoter region together with the recognition sites of the restriction enzymes. $m$ in an open circle: methyl groups. Scissor cartoon: successful endonucleolytic cleavage.

\section{T90 promoter hypermethylation was detected in three T90 white mutants}

DNA methylation is an important and frequently occurring driver of epigenetic changes, which can attenuate binding by the transcription regulatory proteins, thereby inhibiting the activation of target genes (Medvedeva et al., 2014; Yang et al., 2020). We investigated whether an epigenetic event interfering with the endogenous GUS expression in T90 white mutants 
could be related to DNA methylation. To detect differences in the methylation pattern between T90 and T90 white mutants, we took advantage of restriction digestion enzymes, whose endonucleolytic activities are differentially affected by DNA methylation patterns in their recognition sites. We focused on the short $113 \mathrm{bp}$ region because deletion of this region led to a complete absence of GUS gene expression during nodulation. We performed restriction digestion of genomic DNA (gDNA) followed by Polymerase Chain Reaction (PCR). Four enzymes - Haell, ApaLI and Avall that are sensitive to DNA methylation and Bpil that is insensitive were chosen because their recognition sites were within or directly adjacent to this 113 bp region (Fig. 4a). Unlike Bpil that cleaves the target DNA regardless of the methylation pattern, endonucleolytic cleavage by HaellI, ApaLI or Avall is blocked by a specific methylation signature present at their recognition sites (rebase.neb.com). Consequently, amplification of the DNA region of interest in a PCR using gDNA digested with Haell, ApaLI or Avall as a template is only successful when their recognition sites were methylated. We subjected gDNA extracted from roots of $L$. japonicus Gifu, T90 and T90 white mutants grown in the absence of microsymbionts to restriction digestion by either one of these enzymes. A promoter region of the NIN gene that did not contain any recognition site could be successfully amplified with digested gDNA from all genotypes, demonstrating that the gDNA quality was suitable for PCR after restriction digestion (Fig. 4b; bottom panel). When the gDNA was digested with Haell, ApaLI or Avall, a PCR product corresponding to CBP1 promoter was obtained using digested gDNA from T90 white mutants as the amplification template, but not with that from Gifu or T90 (Fig. 4b; top panel). In contrast, no PCR product was obtained with Bpil-digested gDNA regardless of the genotype. Altogether, these results indicated that all three T90 white mutants were hypermethylated within and around this 113 bp region (Fig. 3c).

\section{CBP1 is regulated by the CCaMK/Cyclops complex}

The observations that the T90 GUS gene expression can be induced by exposure to rhizobia and an AM fungus as well as spontaneously by autoactive CCaMK suggested that the T90 promoter is likely subject to CCaMK/Cyclops regulation. We used transient expression assays in Nicotiana benthamiana leaves to test whether the CCaMK/Cyclops protein complex could transcriptionally induce expression of a GUS reporter gene under the control of the CBP1 promoter or the T90 promoter (Fig. 5a, S4a-b). A 2870 bp region 5' of the transcriptional start site of CBP1 was cloned together with the 177 bp 5' untranslated region (UTR) of CBP1 from L. japonicus Gifu (CBP1-2870pro). The expression of the reporter gene driven by $T 90_{\text {pro }}$ or CBP1. 2870pro was induced in the presence of Cyclops and the autoactive CCaMK ${ }^{1-314}$ (CCaMK ${ }^{1-}$ ${ }^{314} /$ Cyclops; Fig. 5a,S4b). In addition, T90 pro achieved transcriptional activation mediated by $\mathrm{CCaMK}^{\mathrm{T} 265 \mathrm{D}} /$ Cyclops (Fig. S4a). A 928 bp stretch of CBP1 promoter corresponding to the region 3' to the T90 T-DNA insertion site (CBP1_-928pro; fused to the CBP1 5' UTR in the reporter 
fusion) did not achieve reporter gene induction by CCaMK ${ }^{1-314} /$ Cyclops (Fig. 5a,S4b). These observations together indicated the presence of putative cis-regulatory elements responsive to CCaMK/Cyclops-mediated transactivation between -2870 and -928 bp of the CBP1 promoter.

\section{CBP1 promoter dissection revealed a novel Cyclops response cis-regulatory element}

To identify the CCaMK/Cyclops-responsive cis-regulatory element, we generated a promoter 5 ' deletion series and investigated reporter gene activation by $\mathrm{CCaMK}^{1-314} /$ Cyclopsmediated transactivation in transient expression assays in $N$. benthamiana leaves (Fig. $\mathbf{5 b}$ d,S4c-e). The 5' deletion series was built on the basis of T90 pro:GUS (constructed in the same way as those tested in Fig. 3). Each construct comprises a CBP1 promoter stretch of variable length. The nucleotide position at the 5 ' end of the deletions is based on the coordinates of the $C B P 1$ promoter (see Fig. 1a). An initial comparison of the transactivation strength across the deletion series revealed a reduction to approximately $50 \%$ when comparing -2780 and -2365 bp and a complete loss of activity when comparing -1327 to -979 bp (Fig. 5b), indicating that these two regions might contain the responsible cis-elements. Testing further deletions that were ca. $100 \mathrm{bp}$ different in length within these two regions revealed that the series between 2870 and -2365 exhibited large variations in responsiveness between replicates and was therefore not investigated further. In the -1327 to -979 series, fragments equal to or longer as -1092 resulted in similar reporter gene activation mediated by CCaMK ${ }^{1-314} /$ Cyclops, while construct - 979 was inactive, suggesting the presence of relevant cis-element(s) between -1092 and -979 bp (Fig. 5c,S4c). By testing a higher resolution series with 35 bp to 50 bp length difference, we narrowed down the responsible cis-element to the 30 nucleotides between -997 and -967 bp that contained an almost perfect (only two non-matching basepairs; Fig. 5e) palindromic sequence of $16 \mathrm{bp}$. We called this element "Cyclops-response element within the CBP1 promoter" (CYC-RE $\left.E_{C B P 1}\right)$ because a loss of reporter gene induction by $\mathrm{CCaMK}^{314} /$ Cyclops was observed when this element was deleted (Fig. 5d,S4d). To test the relevance of $C Y C-R E_{C B P 1}$ in the context of the T90 promoter, we mutated or deleted CYC-RE

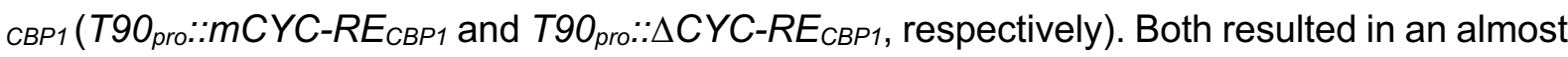
complete loss of $\mathrm{CCaMK}^{1-314} /$ Cyclops-mediated transcriptional activation, indicating that $C Y C$ $R E_{C B P 1}$ was essential for this transcriptional activation (Fig. 5e,S4e). Moreover, $C Y C-R E_{C B P 1}$ fused to a $35 \mathrm{~S}$ minimal promoter (CYC-RE $\left.E_{C B P 1}: 35 S \min _{\text {pro }}\right)$ was sufficient for the activation of reporter gene (Fig. 5e,S4e). These results together indicated that $C B P 1_{\text {pro }}$ (and $T 90_{\text {pro }}$ in the context of T90 genome) is regulated by the CCaMK/Cyclops complex through a cis-regulatory element $C Y C-R E_{C B P 1}$. 


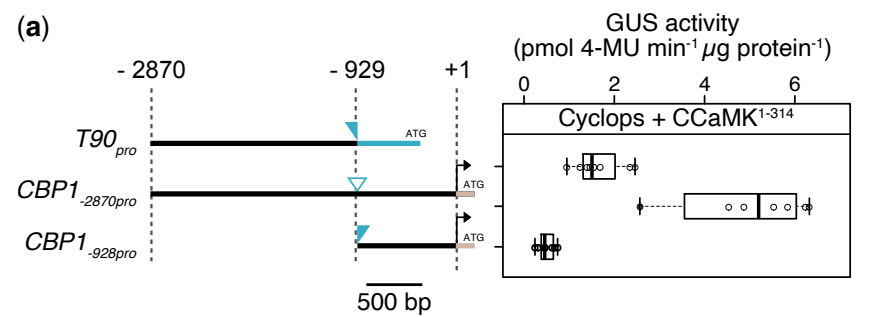

(b)

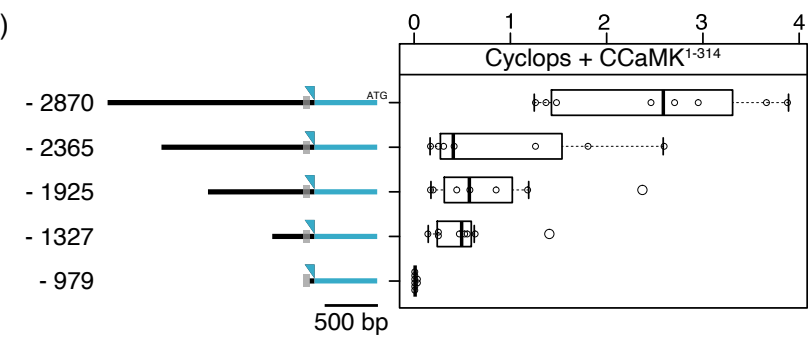

(c)

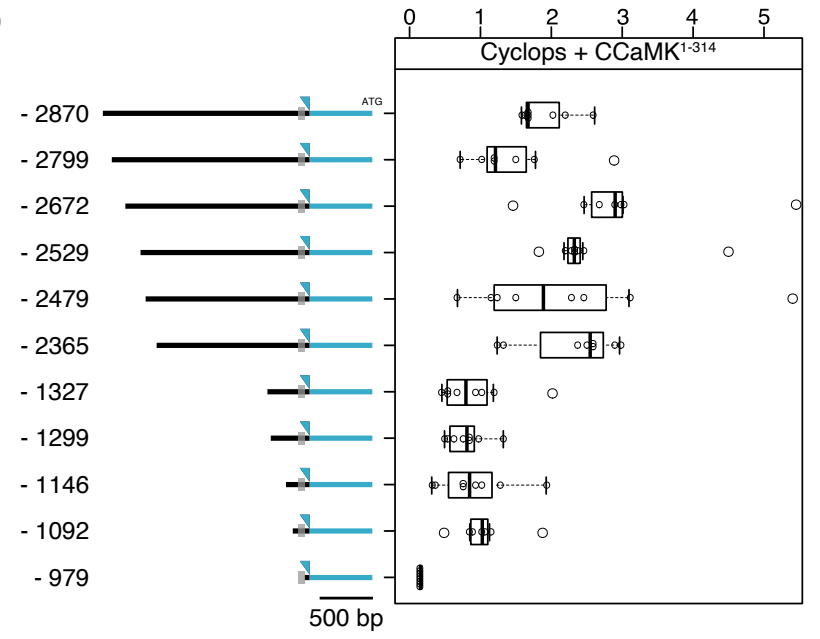

(d)

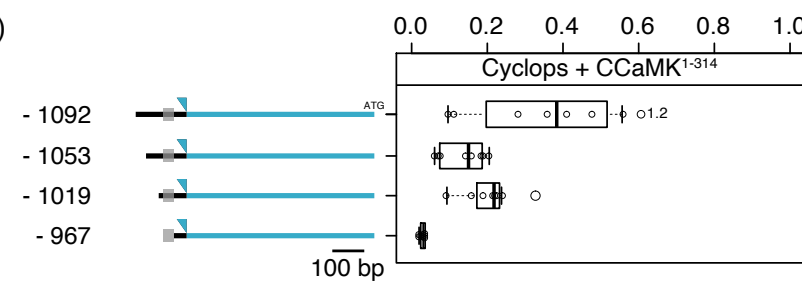

(e)

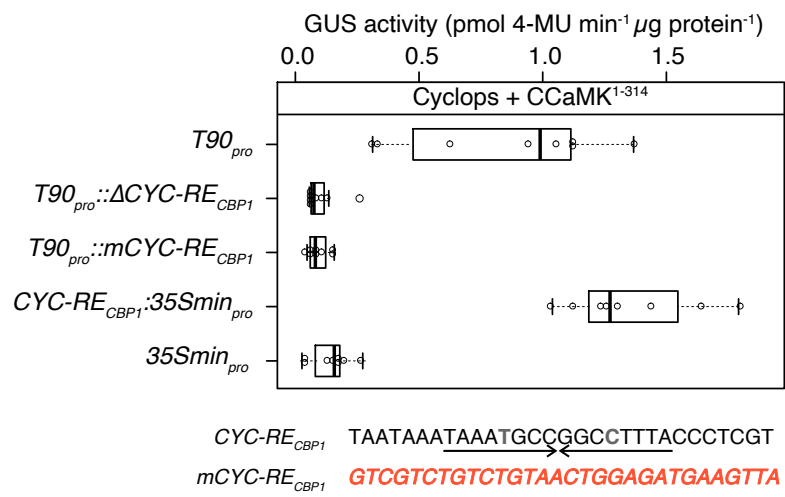

Fig. 5 A cis-element in the promoter of CBP1 is necessary and sufficient for the CCaMK ${ }^{1-314} /$ Cyclops mediated transactivation of promoter:GUS reporter fusions in Nicotiana benthamiana leaf cells. (a-e) $N$. benthamiana leaf cells were transformed with T-DNAs carrying a GUS reporter gene driven by either of the indicated promoters: (a) the T90 promoter (labelled as $T 90_{\text {pro }}$ in a \& d or -2870 in $\mathrm{b}-\mathrm{c}$ ); one of the two CBP1 promoter regions (CBP1-2870pro or CBP1. 928pro); (b-d) promoter deletion series generated in the context of $T 90_{\text {pro }}$ including promoter regions that were (b) ca. 300 - 500 bp different in length, (c) ca. 50 to $100 \mathrm{bp}$ different in length within -2870 to $-2025 \mathrm{bp}$ or -1327 to 979 bp, (d) ca. 35 - 50 bp different in length within -1092 to $-967 \mathrm{bp}$; (e) $T 90_{\text {pro, }}$ T90 pro with the 30 nt long ciselement $\left(C Y C-R E_{C B P 1}\right)$ mutated or deleted $\left(T 90_{\text {pro }}:: m C Y C-R E_{C B P 1}\right.$ or

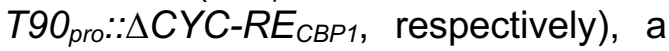
$35 S$ minimal promoter $\left(35 S^{2}\right.$ in $\left._{\text {pro }}\right)$, or CYC-RE $E_{C B P 1}$ fused to $35 S$ min $_{\text {pro }}$ (CYC$\left.R E_{C B P 1}: 35 S \min _{\text {pro }}\right)$. The numbers in (ad) indicating length of promoter were based on CBP1 promoter taking its transcriptional start site as +1 . Left of the boxplots in (a-d) are graphic illustrations of the promoter regions driving the GUS reporter gene with the open triangle and grey boxes illustrating the T-DNA insertion site projected onto the CBP1 promoter and of CYC-RE $E_{C B P 1}$, respectively. Black and blue colour label regions originating from the $L$. japonicus wild-type genome and from the T-DNA in T90, respectively. The larger experimental set-up boxplots including the results of negative controls is presented Fig. S4 with statistical tests. Note the palindromic sequence within the $C Y C-R E_{C B P 1}$ highlighted by opposing arrows. Interrupted by only two non-matching basepairs highlighted in grey \& bold. 


\section{CYC-RE $E_{C B P 1}$ drives gene expression during RNS and AM}

CYC-RE $E_{C B P 1}$ is located only 39 bp 5' of the T-DNA insertion site in T90 and we noticed that $C Y C-R E_{C B P 1}$ sits within the hypermethylated region in the T90 white mutants (Fig. 3). Given the necessity and sufficiency of $C Y C-R E_{C B P 1}$ for CCaMK/Cyclops-mediated transcriptional activation (Fig. 5) as well as the common requirement of this protein complex in
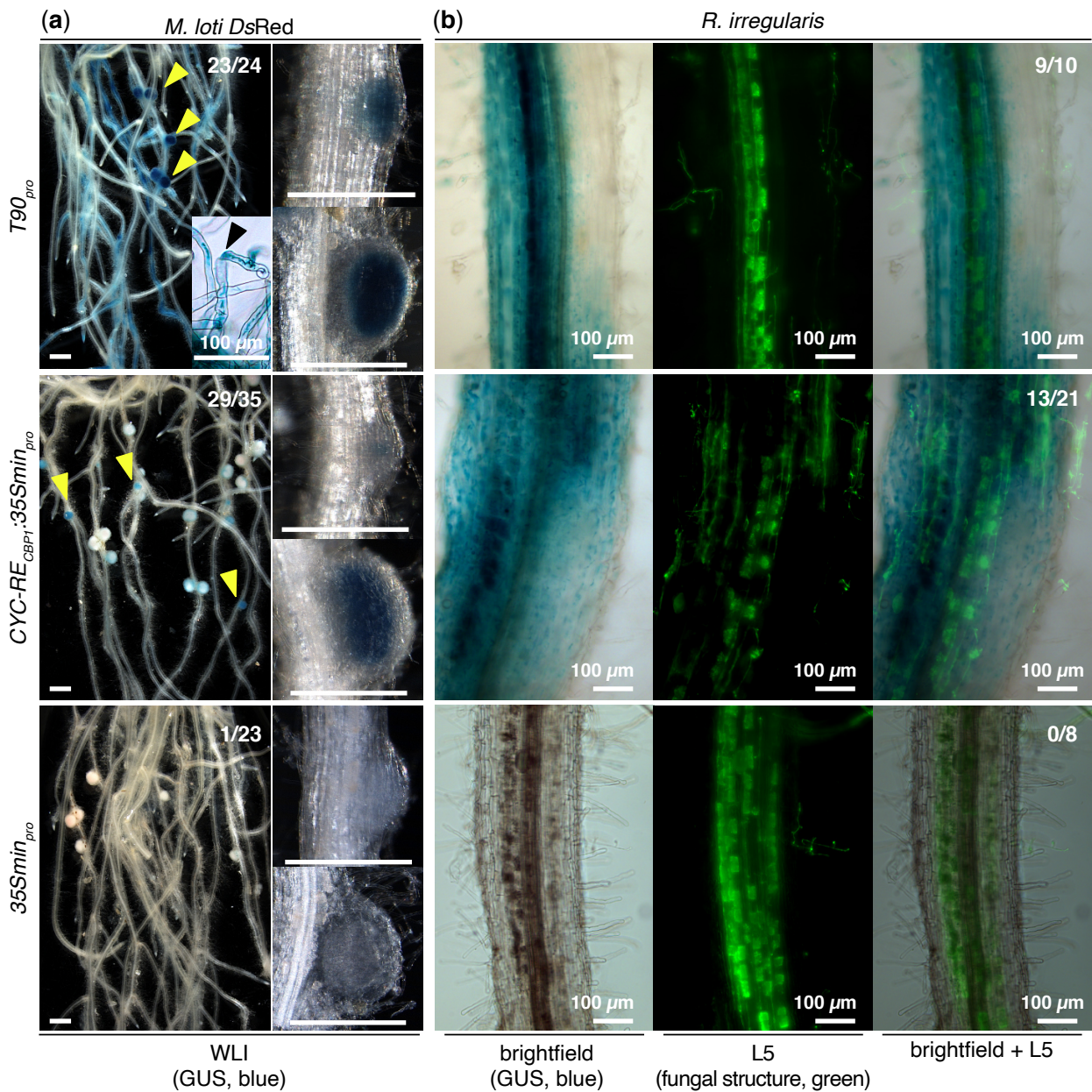

Fig. 6 Spatio-temporal GUS expression driven by $C Y C-R E_{C B P 1}$ in $L$. japonicus hairy roots during nodulation and mycorrhization. $L$. japonicus Gifu hairy roots were transformed with T-DNAs carrying a Ubq10 pro:NLS-GFP transformation marker together with a GUS reporter gene driven by the either of the following promoters: the T90 promoter (T90 pro), a $35 \mathrm{~S}$ minimal promoter $\left(35 S \operatorname{Smin}_{\text {pro }}\right)$, or $C Y C-R E_{C B P 1}$ fused to $35 S \min _{\text {pro }}\left(C Y C-R E_{C B P 1}: 35 S \min _{\text {pro }}\right)$. Transformed roots and nodules were analysed (a) 10 - 14 dpi with M. loti DsRed or (b) 12 dpi with $R$. irregularis. Note that GUS activity was detected in root hairs (black arrowhead in a) in the roots transformed with T90 pro:GUS but not with CYC-RE ${ }_{C B P 1}: 35 S \min _{\text {pro: }}$ GUS (for additional support see Fig. S3e). Overall, T90 pro:GUS gave stronger GUS activity (i.e. darker blue colour) in nodules than CYC-RE $E_{C B P 1}: 35 S \min _{\text {pro: }}$ GUS (yellow arrowheads; compare the overview images of root systems). Note that 35 Smin $_{\text {pro: }}$ GUS did not show any GUS activity during nodulation or mycorrhization except for GUS activity in vasculature in rare cases. Green: Alexa Fluor-488 WGA-stained R. irregularis visualised with a Leica Filter Cube L5. \#/\#, number of plants showing GUS activity in nodules or root cortex / total number of transgenic root systems analysed. Bars, $1 \mathrm{~mm}$ unless stated otherwise. 
AM and RNS, we hypothesised that this cis-element might be responsible for the symbiosesspecific GUS expression in T90. To test this, a GUS or DoGUS (a variant of GUS) gene driven by $C Y C-R E_{C B P 1}$ fused to a $35 S$ minimal promoter $\left(C Y C-R E_{C B P 1}: 35 S m i n_{\text {pro }}\right)$ or the T90 promoter $\left(T 90_{\text {pro }}\right)$ was introduced into $L$. japonicus Gifu hairy roots, followed by inoculation with $M$. loti DsRed or the AM fungus Rhizophagus irregularis (Fig. 6,S3e\&d). During nodulation, GUS

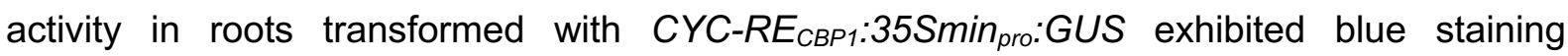
specifically in nodule primordia and nodules, but not root hairs (Fig. 6a). The same promoter:reporter fusions constructed with DoGUS instead of GUS led to similar results (Fig. S3d). During mycorrhization, blue staining were detected in segments in roots transformed

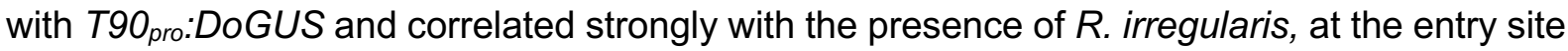
of fungal hyphae crossing the epidermis (Fig. S3e) and in cortical cells containing arbuscules

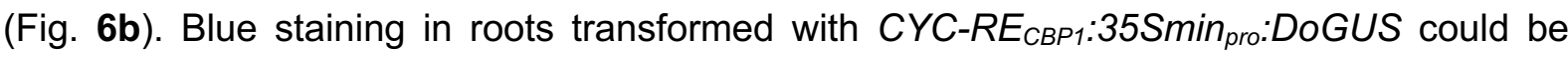
specifically detected in the cortex in segments of roots, where cells were infected by $R$. irregularis (Fig. 6b). In both cases, GUS activity was visibly stronger in cells that were just invaded or had developing arbuscles, compared to those that the arbuscles almost occupying the entire cells. By contrast, roots transformed with GUS or DoGUS driven by the 355 minimal promoter did not display GUS activity during RNS or AM. Roots transformed with either one of the mentioned fusion constructs grown in the absence of microsymbionts exhibited only rarely blue staining, and if so, in vasculature or root tips regardless of the reporter fusion. We concluded that $C Y C-R E_{C B P 1}$ confers $A M-$ and RNS- related gene expression specifically in the fungal-colonised root cortical cells and in nodules, respectively.

\section{The CBP1 promoter drives gene expression during RNS}

We observed that $C Y C-R E_{C B P 1}$ in the context of the T90 promoter mediated responsiveness to transactivation by CCaMK/Cyclops and conferred gene expression during symbioses. The T-DNA insertion in T90 physically separated the promoter of CBP1 into two regions: one containing $C Y C-R E_{C B P 1}$ located $5^{\prime}$ of the insertion (5' region) and the other $3^{\prime}$ of the insertion (3' region). It has been hypothesized previously that the 5' region enhances CBP1 expression during symbiosis while the $3^{\prime}$ region was responsible for its basal expression (Tuck, 2006). To investigate the role of the 3' region in more detail, we generated $L$. japonicus Gifu hairy roots transformed with a GUS reporter gene driven by $C B P 1_{-2870 p r o}$ that represents the "native" full length promoter comprising both the 5' and the 3' region or CBP1-928pro consists of only the 3' region (Fig. 1b,4a). Transgenic roots were analysed 14 or 21 dpi with M. loti DsRed for GUS expression (Fig. S5). CBP1-2870pro:GUS-transformed roots exhibited strong blue staining in nodules, vasculature tissue, lateral root primordia and root tips (93\% of transgenic root systems displaying blue staining in nodules). In comparison, blue staining in CBP1. 928pro:GUS-transformed roots was observed in the same tissue and organ types, however at a lower efficiency (ca. $50 \%$ of transgenic root systems displaying blue staining in nodules), and 
the blue staining was overall visibly weaker in nodules. These observations were consistent with the hypothesis that the 5' region enhances $C B P 1$ expression during nodulation.

\section{Discussion}

\section{The CBP1 promoter comprises at least 4 expression-modulating regions}

With the goal to uncover regulatory elements involved in symbiosis, we investigated regulatory circuits underlying the symbiosis-specific GUS expression of the L. japonicus promoter tagging line T90. We observed that the T90 GUS expression can be largely recapitulated in hairy roots transformed with a GUS reporter gene driven by a region between -2870 and -967 bp of the CBP1 promoter fused to the same T-DNA border found in the genomic arrangement of the T90 line. The expression pattern achieved by this region matches all key aspects of that of the T90 line: in root hairs and nodules in presence of M. loti; as well as root epidermis and cortical cells when roots were colonised by an AM fungus; and in both symbioses, absent from other tissues such as root vasculature and root tips. We therefore used this transgenic setting as the starting point to dissect the promoter function using a classical promoter deletion series. Our analysis revealed at least four regions/elements with significant impact on CBP1 expression (Fig. 7).

\section{A 30 bp CYC-RE}

We identified a 30-nucleotide long element named $C Y C-R E_{C P B 1}$ within the region -997 and -967 bp which is only 39 bp 5' of the T-DNA insertion in T90 (Fig. 7). This element, when equipped with a minimal promoter, was able to confer gene expression during both RNS and AM (Fig. 6), specifically in nodules and infected cortical cells, respectively. The features of $C Y C-R E_{C B P 1}$ provide a plausible explanation for the common and symbioses-specific GUS activity in T90: as a result of the T-DNA insertion in T90, the promoterless GUS gene was coincidently brought in proximity at the 3' of $C Y C-R E_{C B P 1}$, a cis-element that drives gene expression during colonisation by rhizobia and AM fungi. In the presence of microsymbionts, the GUS gene was consequently activated generating a symbioses-specific expression pattern. Our results provide evidence of the involvement of CCaMK/Cyclops in mediating activation of the CBP1 gene encoding a putative calcium-binding protein for both RNS and $\mathrm{AM}$, through a common cis-element $C Y C-R E_{C B P 1}$.

\section{A 54 bp region 5' of CYC-RE $E_{C B P 1}$ (Root Hair Element $\left(R H E_{C B P 1}\right)$ ) is essential for gene expression in root hairs}

A region between -1146 and -1092 bp was necessary for GUS expression in patches of root hairs in proximity to or undergoing IT formation (Fig. S3c). Expression in root hairs could not be achieved when the region was deleted from the T90 promoter or when CYC-RE $E_{C B P 1}$ was tested on its own. 


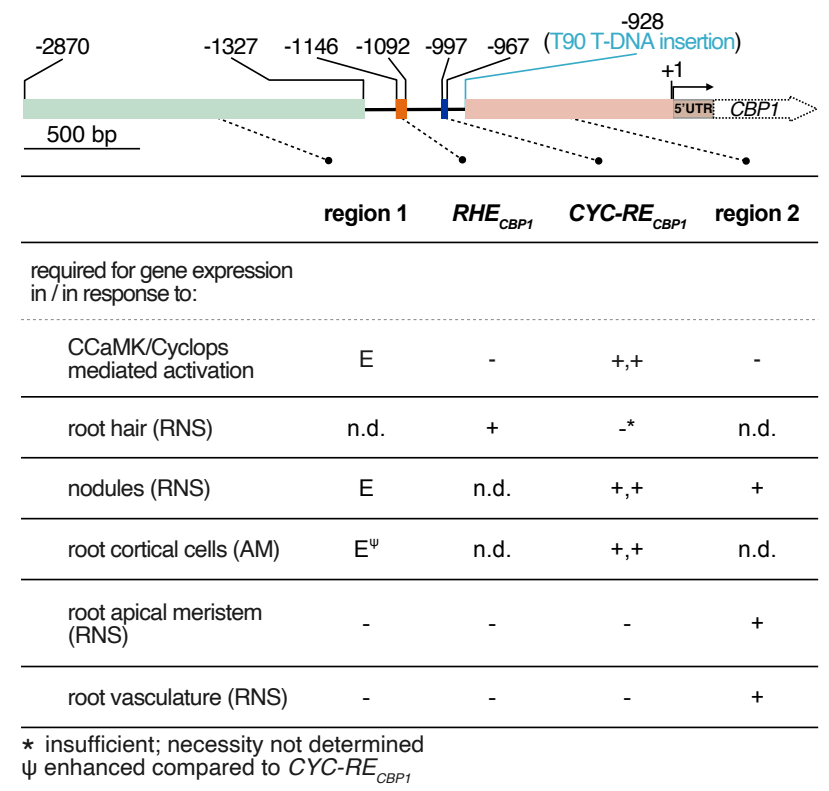

Fig. 7 Four regulatory regions of the $C B P 1$ promoter and their impact on gene expression. $R H E_{C B P 1}$ and $C Y C$ $R E_{C B P 1}$ confer tissue specificity while region 1 and region 2 contribute to the expression strength of the CBP1 gene. $+:$ necessary; - : not necessary; E: enhancing expression strength; +,+: necessary and sufficient; n.d. : not determined. Note that the quality attribute "necessary" is based on results obtained in different promoter contexts. For $R_{H E E_{C B 1} \text { and } C Y C \text { - }}$ $R E_{C B P 1}$, this annotation is based on the T90 promoter context and region 2 may contain at least partially redundant functions. The dotted arrow indicating it is not drawn to scale.

\section{The region 3' of the CYC-RE}

The region 3' of $C Y C-R E_{C P B 1}$, between -928 and -1 (region 2 in Fig. 7), had on its own very little or no responsiveness to CCaMK/Cyclops mediated gene activation in $N$. benthamiana leaf cells, but significantly boosted such responsiveness in the presence of its 5' region containing $C Y C-R E_{C B P 1}$ (Fig. 5a). Interestingly, region 2, despite being devoid of a CCaMK/Cyclops response in in $N$. benthamiana leaf cells, conferred gene expression in early nodule development, root vasculature and root tips in $L$. japonicus hairy roots infected by $M$. loti.

\section{The region 5' of $R H E_{C B P 1}$ contains probably multiple regulatory elements}

A region between -2870 and -1327 bp (region 1 in Fig. 7) significantly enhances gene activation mediated by CCaMK/Cyclops in $N$. benthamiana leaf cells. Interestingly, the inclusion of this region in $N$. benthamiana transient assays resulted in much larger variation between different leaf discs and unusually strong inter-experimental variation. We interpret this variation as a sensitivity of the underlying regulatory machinery to subtle diurnal, developmental or environmental differences of the leaf tissue that are not observed in other promoter fusions. Deletion of this region did not result in loss of reporter expression in nodules, rather seemed to affect the expression strength of the reporter gene (Fig. 3b). Hence we focussed only on the reporter gene expression pattern in the roots and did not further investigate a possible quantitative contribution of the -2780 and -1327 bp region.

In summary, we propose a model in which the CBP1 promoter contains at least 4 distinct regulatory regions that contribute to the expression strength or the tissue specificity or the stimulus specificity of the CBP1 expression (Fig. 7). 


\section{The T90 GUS expression pattern is governed by the CCaMK/Cyclops complex}

By performing transactivation assays in $N$. benthamiana leaves, we observed that CYC$R E_{C B P 1}$ equipped with a minimal promoter was sufficient for CCaMK/Cyclops-mediated transcriptional activation (Fig. 5e). Three CYC-REs identified earlier come from the promoters of two RNS-induced genes, NIN and ERN1 (CRE and CYC-RE $E_{E R N 1}$, respectively; Singh et al., 2014; Cerri et al., 2017) and an AM-induced gene, RAM1 (AMCYC-RE; Pimprikar et al., 2016). The core of $C Y C-R E_{C B P 1}$ is semi-palindromic and shares high sequence similarity with $C Y C$ $R E_{R A M 1}$ and to a lesser extent with $C R E$ and $C Y C-R E_{E R N 1}$. Similar to the situation of the three previously identified $C Y C-R E s$, deletion or mutation of $C Y C-R E_{C B P 1}$ drastically impaired Cyclops-mediated transcriptional activation (Fig. 5e). These observations together suggest that the induction of the GUS gene in T90 is at least in the nodules, achieved by CYC-RE $E_{C B P 1}$ via CCaMK/Cyclops-mediated activation and that it contributes essentially, but can not on its own, mediate expression in root hairs (Fig. 6).

In L. japonicus, the expression of CBP1 during nodulation in roots is likely enhanced by the presence of $C Y C-R E_{C B P 1}$ in its promoter (Fig. S5). This conclusion is consistent with the fact that $C B P 1$ is expressed at a reduced level in T90 roots in which the T-DNA insertion presumably reduces or entirely blocks the activity of this cis-element (Webb et al., 2000). Nevertheless, current evidence seems to suggest that the Cyclops-regulated enhancement of CBP1 expression is dispensable for symbiosis because neither T90 nor T90 white mutants are impaired in RNS or AM (Fig. 1,2,S4). Given the conserved function of the CaM domain to interact with $\mathrm{Ca}^{2+}$ ions, other calcium-binding proteins (e.g., those that identified in Liao et al., 2017) could function redundantly with $C B P 1$ during symbiosis. Alternatively, it is possible that the residual expression of CBP1 conferred by the 928 bp regulatory region 3' of the T-DNA insertion site in T90 (region 2 in Fig. 6) is sufficient for endosymbiosis or that the impact of the reduced expression levels could not be detected by phenotyping the number of nodules and shoot dry weight of plants (Fig. S4).

\section{The T90 white mutant phenotype is caused by cytosine methylation of the T90 promoter}

The initial forward genetic approach to screen an EMS-mutagenised T90 population led to the identification of the T90 white mutants (Fig. 2). Based on an analysis using cytosine methylation-sensitive restriction enzymes, we detected hypermethylation within and around in a 113 bp regulatory region of its GUS gene (Fig. 4). This region contains the Cyclops target cis-element, $C Y C-R E_{C B P 1}$, which is capable on its own, to drive gene expression during AM and RNS (Fig. 6b). Cytosine methylation is a well-studied phenomenon and frequently associated with heterochromatin-based gene inactivation (Iwasaki \& Paszkowski, 2014). The element's ability to achieve gene expression during both symbioses and its hypermethylation in the T90 white mutants are in line with the T90 and T90 white phenotype. We conclude from 
all the above that the difference in cytosine methylation in and around $C Y C-R E_{C B P 1}$ is the likely cause for the inability the T90 white mutants to express their GUS genes. In addition, the observation made with T90 white mutants indicate that Cyclops activity can be severely impeded by DNA methylation of its target sites. As DNA methylation is overall dynamically altered during nodulation (Satgé, et al., 2016), studying the methylation of cis-regulatory elements may reveal another layer of transcriptional regulation during symbiotic development.

\section{Regulatory elements governing gene activation in both AM and RNS}

For most genes that are activated in both RNS and AM, the cis-elements responsible for this common induction are not yet known. Only one other element, an AT-rich motif identified in the promoter of Medicago truncatula ENOD11 gene, was reported important for high-level gene expression during both RNS and AM (Boisson-Dernier et al., 2005). ENOD11 is one of the earliest marker genes induced by rhizobia as well as an AM fungus (Chabaud et al., 2002; Journet et al., 2001).

The discovery of $C Y C-R E_{C B P 1}$ supported a possible scenario that at least a subset of the genes induced during both RNS and AM development could be regulated by the CCaMK/Cyclops complex. This hypothesis is in line with the observations that CBP1 expression is specifically induced in roots upon Nod factor treatment or inoculation with M. loti (data not shown) as well as with the AM fungus $R$. irregularis; and the upregulation of CBP1 during nodulation is dependent on functional Cyclops, NFR1 and NFR5 genes (data retrieved from LotusBase, Webb et al., 2000; Mun et al., 2016). Our observation that four regions of the $C B P 1$ promoter impact its gene expression suggest that additional pathways are in play to achieve tissue-specific expression pattern and enhance gene expression.

\section{Acknowledgements}

The authors thank Judith K. Webb for the grounding work on the transgenic line T90 and David Chiasson for providing a plasmid containing the DoGUS gene that is adapted for the Golden Gate cloning system. E Jensen (née Tuck) thanks Aberystwyth University for a PhD scholarship, which funded the EMS screen. This work was supported by SFB924 "Molecular mechanisms regulating yield and yield stability in plants". This project has received funding from the European Research Council (ERC) under the European Union's Seventh Framework Programme (FP7/2007-2013) under grant agreement $n^{\circ} 340904$.

\section{Author Contribution}

MP performed mutagenesis of T90 seed to generate the T90 EMS mutant population (Fig. 2a) and EJ conducted screen B. SB performed screen A and investigated the T90 white phenotype. XG performed experiments and collected and analysed data (Fig.1, 2b-d, 3 - 5 and 
all supplementary figures). XG and MP drafted and finalised the manuscript. EJ contributed to manuscript editing.

\section{Data Availability}

All raw data including raw images are either available in the supplement or in repositories. Sequences of constructs and key plasmids necessary for reproducing the results will be made available at Addgene. 


\section{References}

Akamatsu A, Nagae M, Nishimura Y, Romero Montero D, Ninomiya S, Kojima M, Takebayashi Y, Sakakibara H, Kawaguchi M, Takeda N. 2020. Endogenous gibberellins affect root nodule symbiosis via transcriptional regulation of NODULE INCEPTION in Lotus japonicus. The Plant Journal: tpj.15128.

Antolín-Llovera M, Petutsching EK, Ried MK, Lipka V, Nürnberger T, Robatzek S, Parniske M. 2014. Knowing your friends and foes - plant receptor-like kinases as initiators of symbiosis or defence. New Phytologist 204: 791-802.

Banba M, Gutjahr C, Miyao A, Hirochika H, Paszkowski U, Kouchi H, Imaizumi-Anraku $\mathbf{H}$ 2008. Divergence of evolutionary ways among common sym genes: CASTOR and CCaMK show functional conservation between two symbiosis systems and constitute the root of a common signaling pathway. Plant and Cell Physiology 49: 1659-1671.

Banhara A, Ding Y, Kühner R, Zuccaro A, Parniske M. 2015. Colonization of root cells and plant growth promotion by Piriformospora indica occurs independently of plant common symbiosis genes. Frontiers in Plant Science 6. 667.

Boisson-Dernier A, Andriankaja A, Chabaud M, Niebel A, Journet EP, Barker DG, de Carvalho-Niebel F. 2005. MtENOD11 gene activation during rhizobial infection and mycorrhizal arbuscule development requires a common AT-rich-containing regulatory sequence. Molecular Plant-Microbe Interactions 18: 1269-1276.

Bowler MW, Cliff MJ, Waltho JP, Blackburn GM. 2010. Why did Nature select phosphate for its dominant roles in biology? New Journal of Chemistry 34: 784-794.

Breakspear A, Liu C, Roy S, Stacey N, Rogers C, Trick M, Morieri G, Mysore KS, Wen J, Oldroyd GE et al. 2014. The root hair "infectome" of Medicago truncatula uncovers changes in cell cycle genes and reveals a requirement for Auxin signaling in rhizobial infection. Plant Cell 26: 4680-4701.

Cerri MR, Frances L, Laloum T, Auriac MC, Niebel A, Oldroyd GED, et al. 2012. Medicago truncatula ERN transcription factors: regulatory interplay with NSP1/NSP2 GRAS factors and expression dynamics throughout rhizobial infection. Plant Physiology 160: 2155-2172.

Cerri MR, Wang Q, Stolz P, Folgmann J, Frances L, Katzer K, Li X, Heckmann AB, Wang TL, Downie JA et al. 2017. The ERN1 transcription factor gene is a target of the CCaMK/CYCLOPS complex and controls rhizobial infection in Lotus japonicus. New Phytologist 215: 323-337.

Charpentier M, Bredemeier R, Wanner G, Takeda N, Schleiff E, Parniske, M. 2008. Lotus japonicus Castor and Pollux are ion channels essential for perinuclear calcium spiking in legume root endosymbiosis. Plant Cell 20: 3467-3479.

Demina IV., Persson T, Santos P, Plaszczyca M, Pawlowski K. 2013. Comparison of the nodule vs. root transcriptome of the actinorhizal plant Datisca glomerata: actinorhizal nodules contain a specific class of defensins. PLOS ONE 8: e72442.

Endre G, Kereszt A, Kevei Z, Mihacea S, Kaló P, Kiss GB. 2002. A receptor kinase gene regulating symbiotic nodule development. Nature 417: 962-966.

Fowler D, Coyle M, Skiba U, Sutton MA, Cape JN, Reis S, Sheppard LJ, Jenkins A, Grizzetti B, Galloway N, et al. 2013. The global nitrogen cycle in the twenty- first century. Philosophical Transactions of the Royal Society B: Biological Sciences 368:20130164

Gobbato E, Marsh JF, Vernié T, Wang E, Maillet F, Kim J, Miller JB, Sun J, Bano SA, Ratet $P$, et al. 2012. A GRAS-type transcription factor with a specific function in mycorrhizal signaling. Current Biology 22: 2236-2241.

Gossmann JasmineA. 2011. Multiple molecular components contribute to genotype specific compatibility of the root nodule symbiosis. Doctoral thesis, University of Munich, Munich Germany.

Gossmann JA, Markmann K, Brachmann A, Rose LE, Parniske M. 2012. Polymorphic infection and organogenesis patterns induced by a Rhizobium leguminosarum isolate from Lotus root nodules are determined by the host genotype. New Phytol 196: 561573. 
Groth M, Takeda N, Perry J, Uchida H, DräxI S, Brachmann A, Sato S, Tabata S, Kawaguchi M, Wang TL, Parniske M 2010. NENA, a Lotus japonicus homolog of Sec13, is required for rhizodermal infection by arbuscular mycorrhiza fungi and rhizobia but dispensable for cortical endosymbiotic development. The Plant cell 22: 2509-2526.

Gutjahr C, Sawers RJH, Marti G, Andrés-Hernández L, Yang SY, Casieri L, Angliker H, Oakeley EJ, Wolfender JL, Abreu-Goodger C, et al. 2015. Transcriptome diversity among rice root types during asymbiosis and interaction with arbuscular mycorrhizal fungi. Proceedings of the National Academy of Sciences of the United States of America 112. 6754-6759.

Handberg K, Stougaard J 1992. Lotus japonicus, an autogamous, diploid legume species for classical and molecular genetics. The Plant Journal 2, 487-496.

Hogekamp C, Arndt D, Pereira P a., Becker JD, Hohnjec N, Kuster H. 2011. Laser microdissection unravels cell-type-specific transcription in arbuscular mycorrhizal Roots, including CAAT-Box transcription factor gene expression correlating with fungal contact and spread. Plant Physiology 157: 2023-2043.

Hoagland DR, Arnon DI 1938. The water-culture method for growing plants without soil. Berkeley: University of California. Revised by Arnon 1950.

Ivanov S, Fedorova EE, Limpens E, de Mita S, Genre A, Bonfante P, Bisseling T. 2012. Rhizobium-legume symbiosis shares an exocytotic pathway required for arbuscule formation. Proceedings of the National Academy of Sciences of the United States of America 109. 8316-8321.

Iwasaki M, Paszkowski J. 2014. Epigenetic memory in plants. The EMBO Journal 33. 1987-1998.

Jefferson, RA 1987. Assaying chimeric genes in Plants: The GUS gene fusion system. Plant Molecular Biology Reporter, 5:387-405.

Jefferson RA, Kavanagh TA, Bevan MW. 1987. GUS fusions: beta-glucuronidase as a sensitive and versatile gene fusion marker in higher plants. The EMBO journal 6. 39013907.

Kim S, Zeng W, Bernard S, Liao J, Venkateshwaran M, Ane JM, Jiang Y. 2019. Ca ${ }^{2+}-$ regulated $\mathrm{Ca}^{2+}$ channels with an RCK gating ring control plant symbiotic associations. Nature Communications 10. 3703.

Kistner C, Winzer T, Pitzschke A, Mulder L, Sato S, Kaneko T, Tabata S, Sandal N, Stougaard J, Webb KJ, et al. 2005. Seven Lotus japonicus genes required for transcriptional reprogramming of the root during fungal and bacterial symbiosis. The Plant cell 17: 2217-2229.

Kumar A, Cousins DR, Liu CW, Xu P, Murray JD. 2020. Nodule inception is not required for arbuscular mycorrhizal colonization of Medicago truncatula. Plants 9. 71.

Lévy J, Bres C, Geurts R, Chalhoub B, Kulikova O, Duc G, Journet EP, Ané JM, Lauber E, Bisseling T, et al. 2004. A putative $\mathrm{Ca}^{2+}$ and calmodulin-dependent protein kinase required for bacterial and fungal symbioses. Science 303: 1361-1364.

Liao J, Deng J, Qin Z, Tang J, Shu M, Ding C, Liu J, Hu C, Yuan M, Huang Y et al. 2017. Genome-wide identification and analyses of calmodulins and calmodulin-like proteins in Lotus japonicus. Frontiers in Plant Science 8, 482.

Liu J, Blaylock LA, Endre G, Cho J, Town CD, VandenBosch KA, Harrison MJ. 2003. Transcript profiling coupled with spatial expression analyses reveals genes involved in distinct developmental stages of an arbuscular mycorrhizal symbiosis. Plant Cell 15. 2106-23.

Liu J, Rutten L, Limpens E, van der Molen T, van Velzen R, Chen R, Chen Y, Geurts R, Kohlen W, Kulikova O, et al. 2019. A remote cis-regulatory region is required for NIN expression in the pericycle to initiate nodule primordium formation in Medicago truncatula. Plant Cell 31: 68-83.

Lueders T, Manefield M, Friedrich MW. 2004. Enhanced sensitivity of DNA- and rRNAbased stable isotope probing by fractionation and quantitative analysis of isopycnic centrifugation gradients. Environmental Microbioloby 6: 73-78. 
Maillet F, Poinsot V, André O, Puech-Pagés V, Haouy A, Gueunier M, Cromer L, Giraudet D, Formey D, Niebel A, et al. 2011. Fungal lipochitooligosaccharide symbiotic signals in arbuscular mycorrhiza. Nature 469: 58-64.

Márquez AJ. 2005. Lotus japonicus handbook. Springer Netherlands.

Medvedeva YA, Khamis AM, Kulakovskiy I v., Ba-Alawi W, Bhuyan MSI, Kawaji H, Lassmann T, Harbers M, Forrest ARR, Bajic VB. 2014. Effects of cytosine methylation on transcription factor binding sites. BMC Genomics 15.119.

Mendiburu F. 2018. Package 'agricolae'. [WWW document] URL https://tarwi.lamolina.edu.pe/ fmendiburu/ [accessed 9 August 2021].

Miller JB, Pratap A, Miyahara A, Zhou L, Bornemann S, Morris RJ, Oldroyd GED. 2013. Calcium/calmodulin-dependent protein kinase is negatively and positively regulated by calcium, providing a mechanism for decoding calcium responses during symbiosis signaling. Plant Cell 25: 5053-5066.

Murray JD, Muni RRD, Torres-Jerez I, Tang Y, Allen S, Andriankaja M, Li G, Laxmi A, Cheng $X$, Wen J, et al. 2011. Vapyrin, a gene essential for intracellular progression of arbuscular mycorrhizal symbiosis, is also essential for infection by rhizobia in the nodule symbiosis of Medicago truncatula. Plant Journal 65: 244-252.

Oldroyd GE. 2013. Speak, friend, and enter: signalling systems that promote beneficial symbiotic associations in plants. Nature Reviews Microbiology 11: 252-263.

Perry JA, Wang TL, Welham TJ, Gardner S, Pike JM, Yoshida S, Parniske M 2003. A TILLING reverse genetics tool and a web-accessible collection of mutants of the legume Lotus japonicus. Plant Physiology 131: 866-871.

Perry JA, Brachmann A, Welham TJ, Binder A, Charpentier M, Groth M, Haage K, Markmann K, Wang TL, Parniske M 2009 TILLING in Lotus japonicus identified large allelic series for symbiosis genes and revealed a bias in functionally defective ethyl methanesulfonate alleles toward glycine replacements. Plant Physiology 151:12811291.

Pimprikar P, Carbonnel S, Paries M, Katzer K, Klingl V, Bohmer MJ, Karl L, Floss DS, Harrison MJ, Parniske M, et al. 2016. A CCaMK-CYCLOPS-DELLA complex activates transcription of RAM1 to regulate arbuscule branching. Current Biology 26: 987-998.

Pimprikar P, Gutjahr C. 2018. Transcriptional regulation of arbuscular mycorrhiza development. Plant and Cell Physiology 59. 673-690.

Feng F, Sun J, Rdhakrishnan GV, Lee T, Bozsóki Z, Fort S, Gavrin A, Gysel K, Thygesen M, Andersen K, et al. 2019. A combination of chitooligosaccharide and lipochitooligosaccharide recognition promotes arbuscular mycorrhizal associations in Medicago truncatula. Nature Communications 10. 5047.

Radutoiu S, Madsen LH, Madsen EB, Felle HH, Umehara Y, Gronlund M, Sato S, Nakamura Y, Tabata S, Sandal N, et al. 2003. Plant recognition of symbiotic bacteria requires two LysM receptor-like kinases. Nature 425: 585-592.

Ried MK, Antolín-Llovera M, Parniske M. 2014. Spontaneous symbiotic reprogramming of plant roots triggered by receptor-like kinases. eLife 3: e03891.

Roux B, Rodde N, Jardinaud MF, Timmers T, Sauviac L, Cottret L, Carrère S, Sallet E, Courcelle E, Moreau S, et al. 2014. An integrated analysis of plant and bacterial gene expression in symbiotic root nodules using laser-capture microdissection coupled to RNA sequencing. Plant Journal 77: 817-837.

Roy S, Breakspear A, Cousins D, Torres-Jerez I, Jackson KJ, Kumar A, Su Y, Krom N, Liu C-W, Udvardi M, et al. 2021. Three common symbiotic ABC-B transporters in Medicago truncatula are regulated by a NIN-independent branch of the symbiosis signalling pathway. Molecular Plant-Microbe Interactions.

Satgé C, Moreau S, Sallet E, Lefort G, Auriac MC, Remblière C, Cottret L, Gallardo K, Noirot C, Jardinaud MF. et al. 2016. Reprogramming of DNA methylation is critical for nodule development in Medicago truncatula. Nature Plants 2: 16166.

Schauser L, Roussis A, Stiller J, Stougaard J. 1999. A plant regulator controlling development of symbiotic root nodules. Nature 402: 191-195.

Schultze M, Kondorosi A. 1998. Regulation of symbiotic root nodule development. Annual Review of Genetics 32: 33-57. 
Sieberer BJ, Chabaud M, Timmers AC, Monin A, Fournier J, Barker DG. 2009. A nuclear-targeted cameleon demonstrates intranuclear $\mathrm{Ca}^{2+}$ spiking in Medicago truncatula root hairs in response to rhizobial nodulation factors. Plant Physiology 151: 1197-1206.

Singh S, Katzer K, Lambert J, Cerri M, Parniske M. 2014. CYCLOPS, a DNA-binding transcriptional activator, orchestrates symbiotic root nodule development. Cell Host and Microbe 15: 139-152.

Stracke S, Kistner C, Yoshida S, Mulder L, Sato S, Kaneko T, Tabata S, Sandal N, Stougaard J, Szczyglowski K, et al. 2002. A plant receptor-like kinase required for both bacterial and fungal symbiosis. Nature 417: 959-962.

Szczyglowski K, Shaw RS, Wopereis J, Copeland S, Hamburger D, Kasiborski B, Dazzo FB, de Bruijn FJ. 1998. Nodule organogenesis and symbiotic mutants of the model legume Lotus japonicus. Molecular Plant-Microbe Interactions 11: 684-697.

Takeda N, Kistner C, Kosuta S, Winzer T, Pitzschke A, Groth M, Sato S, Kaneko T, Tabata S, Parniske M. 2007. Proteases in plant root symbiosis. Phytochemistry 68: 111-121.

Takeda N, Sato S, Asamizu E, Tabata S, Parniske M. 2009. Apoplastic plant subtilases support arbuscular mycorrhiza development in Lotus japonicus. Plant Journal 58: 76677.

Takeda N, Maekawa T, Hayashi M 2012. Nuclear-localized and deregulated calcium- and calmodulin-dependent protein kinase activates rhizobial and mycorrhizal responses in Lotus japonicus. Plant Cell 24: 810-822.

Tirichine L, Imaizumi-Anraku H, Yoshida S, Murakami Y, Madsen LH, Miwa H, Nakagawa T, Sandal N, Albrektsen AS, Kawaguchi M, et al. 2006. Deregulation of a $\mathrm{Ca}^{2+} /$ calmodulin-dependent kinase leads to spontaneous nodule development. Nature 441: 1153-1156.

Topping JF, Wei W, Lindsey K. 1991. Functional tagging of regulatory elements in the plant genome. Development 112: 1009-1019.

Voinnet O, Rivas S, Mestre P, Baulcombe D. 2003. An enhanced transient expression system in plants based on suppression of gene silencing by the $\mathrm{p} 19$ protein of tomato bushy stunt virus. Plant Journal 33: 949-56.

Webb KJ, Skøt L, Nicholson MN, Jørgensen B, Mizen S 2000. Mesorhizobium loti increases root-specific expression of a calcium-binding protein homologue identified by promoter tagging in Lotus japonicus. Molecular Plant-Microbe Interactions 13: 606-616.

Wegel E, Schauser L, Sandal N, Stougaard J, Parniske M 1998. Mycorrhiza mutants of Lotus japonicus define genetically independent steps during symbiotic infection. Mol. Molecular Plant-Microbe Interactions 11: 933-936.

Wickham H, Stryjewski 2011. 40 years of boxplots. [WWW document] URL https://vita.had.co.nz/papers/boxplots.pdf [accessed 9 August 2021]

Yang L, Chen Z, Stout ES, Delerue F, Ittner LM, Wilkins MR, Quinlan KGR, Crossley M. 2020. Methylation of a CGATA element inhibits binding and regulation by GATA-1. Nature Communications 11: 2560.

Yano K, Yoshida S, Müller J, Singh S, Banba M, Vickers K, Markmann K, White C, Schuller B, Sato S, et al. 2008. CYCLOPS, a mediator of symbiotic intracellular accommodation. Proceedings of the National Academy of Sciences of the United States of America 105: 20540-20545.

Zhang C, He J, Dai H, Wang G, Zhang X, Wang C, Shi J, Chen X, Wang D, Wang E. 2021. Discriminating symbiosis and immunity signals by receptor competition in rice. Proceedings of the National Academy of Sciences of the United States of America 118: e2023738118. 